\title{
Secular trends of the impact of overweight and obesity on hypertension in Japan, 1980-2010
}

This article has been corrected since Advance Online Publication, and an erratum is also printed in this issue.

\author{
Masato Nagai ${ }^{1,2,3}$, Takayoshi Ohkubo ${ }^{1,4}$, Yoshitaka Murakami ${ }^{5}$, Naoyuki Takashima ${ }^{1}$, Aya Kadota ${ }^{1,6}$, \\ Naoko Miyagawa ${ }^{1}$, Yoshino Saito ${ }^{1}$, Nobuo $\mathrm{Nishi}^{7}$, Nagako Okuda ${ }^{8}$, Yutaka Kiyohara ${ }^{9}$, Hideaki Nakagawa ${ }^{10}$, \\ Yoshikazu Nakamura ${ }^{11}$, Akira Fujiyoshi ${ }^{1}$, Robert D Abbott ${ }^{6}$, Tomonori Okamura ${ }^{12}$, Akira Okayama ${ }^{13}$, \\ Hirotsugu Ueshima $^{1,6}$ and Katsuyuki Miura ${ }^{1,6}$ for the NIPPON DATA80/90/2010 Research Group ${ }^{14}$
}

The prevalence of overweight (body mass index $(B M I)=25.0-29.9 \mathrm{~kg} \mathrm{~m}^{-2}$ ) and obesity $\left(\geqslant 30.0 \mathrm{~kg} \mathrm{~m}^{-2}\right.$ ) has been increasing over the last several decades in Japan. We examined trends of the impact of overweight and obesity on hypertension (systolic/diastolic blood pressure $\geqslant 140 / 90 \mathrm{~mm} \mathrm{Hg}$ or antihypertensive drugs use) using four national surveys in Japan, from which the participants were randomly sampled from the entire population. Study participants aged 30-79 years were selected for each survey (10 370 in 1980, 8005 in 1990, 5327 in 2000 and 2547 in 2010). The results showed that the impact of overweight and obesity on hypertension had increased significantly $(P=0.040$ and 0.006 in men and women, respectively). From 1980 to 2010 , the multivariable-adjusted odds ratios for hypertension, comparing overweight and obesity with normal weight (BMI $=18.5-24.9 \mathrm{~kg} \mathrm{~m}$ $\left.{ }^{-2}\right)$, went from $1.94(95 \%$ confidence intervals: $1.64,2.28)$ to $2.82(2.07,3.83)$ in men, and from $2.37(2.05,2.73)$ to 3.48 $(2.57,4.72)$ in women. Most of the association was observed in overweight participants, as only $3 \%$ of the Japanese were obese. In addition to the relationship between excessive BMI and other adverse health conditions, the rise in the association with hypertension increases the urgency in addressing weight control. We need to address the overweight and obesity epidemic. Hypertension Research (2015) 38, 790-795; doi:10.1038/hr.2015.81; published online 16 July 2015

Keywords: epidemiology; Japan; obesity; overweight; trend

\section{INTRODUCTION}

Cardiovascular disease mortality, especially stroke mortality, has decreased dramatically during the last several decades in Japan. ${ }^{1}$ This tendency has been attributed to a decrease in the population's blood pressure level. ${ }^{1-3} \mathrm{~A}$ major reason for this blood pressure decrease is considered to be the reduction in salt intake. In northern Japan, salt intake had reached $25 \mathrm{~g}$ per day in the 1950s. ${ }^{4}$ However, it had decreased to $10.5 \mathrm{~g}$ per day in $2011 .{ }^{5}$ In addition, the prevalence of overweight and obesity, which is another determinant of hypertension, has increased. ${ }^{3,5-7}$ Particularly in men, this prevalence has almost doubled during the last several decades. Even though the trend in blood pressure level has decreased, ${ }^{1-3}$ the prevalence of determinants of hypertension has changed. ${ }^{8,9}$ The impact of each determinant on hypertension may also have changed. For instance, Nakamura et al. ${ }^{10}$ showed that the impact of overweight and obesity on hypertension had increased between 1980 and 1990. However, recent long-term trends on the impact of overweight and obesity on hypertension have not been studied.

In the present study, we examined long-term secular changes on the impact of overweight and obesity on hypertension using data from four national surveys during the last 30 years in Japan.

\section{METHODS}

Study participants

The National Integrated Project for Prospective Observation of Noncommunicable Disease and Its Trends in the Aged (NIPPON DATA) is a series of cohort studies conducted using the third National Survey on Circulatory

${ }^{1}$ Department of Public Health, Shiga University of Medical Science, Otsu, Japan; ${ }^{2}$ Radiation Medical Science Center for Fukushima Health Management Survey, Fukushima Medical University, Fukushima, Japan; ${ }^{3}$ Department of Epidemiology, Fukushima Medical University School of Medicine, Fukushima, Japan; ${ }^{4}$ Department of Hygiene and Public Health, Teikyo University School of Medicine, Tokyo, Japan; ${ }^{5}$ Department of Medical Statistics, Toho University School of Medicine, Tokyo, Japan; ${ }^{6}$ Center for Epidemiologic Research in Asia, Shiga University of Medical Science, Otsu, Japan; ${ }^{7}$ Center for International Collaboration and Partnership, National Institute of Health and Nutrition, National Institutes of Biomedical Innovation, Health and Nutrition, Tokyo, Japan; ${ }^{8}$ Department of Health and Nutrition, University of Human Arts and Sciences, Saitama, Japan; ${ }^{9}$ Department of Environmental Medicine, Graduate School of Medical Sciences, Kyushu University, Fukuoka, Japan; ${ }^{10}$ Department of Epidemiology and Public Health, Kanazawa Medical University, Ishikawa, Japan; ${ }^{11}$ Department of Public Health, Jichi Medical University, Tochigi, Japan; ${ }^{12}$ Department of Preventive Medicine and Public Health, School of Medicine, Keio University, Tokyo, Japan and ${ }^{13}$ Research Institute of Strategy for Prevention, Tokyo, Japan

${ }^{14}$ See Acknowledgement for the members of The NIPPON DATA80/90/2010 Research Group.

Correspondence: Dr M Nagai, Radiation Medical Science Center for Fukushima Health Management Survey, Fukushima Medical University, Hikarigaoka 1, Fukushima 960-1295, Japan.

E-mail: mnagai@fmu.ac.jp

Received 12 November 2014; revised 23 April 2015; accepted 27 May 2015; published online 16 July 2015 
Table 1 Characteristics of participants who were recruited from national survey in 1980-2010, Japan

\begin{tabular}{|c|c|c|c|c|c|}
\hline & \multicolumn{4}{|c|}{ Years } & \multirow[b]{2}{*}{$\mathrm{P}$-values ${ }^{\mathrm{a}}$} \\
\hline & 1980 & 1990 & 2000 & 2010 & \\
\hline Number of participants & 4568 & 3357 & 2188 & 1081 & \\
\hline Number of hypertension $(\%)$ & $2285(50.0)$ & $1664(49.6)$ & $1201(54.9)$ & $655(60.6)$ & \\
\hline Mean age (years) (s.d.) & $49.9(12.8)$ & $52.4(12.9)$ & $55.9(12.9)$ & $59.8(12.8)$ & $<0.001$ \\
\hline Normal weight (\%) & 74.5 & 69.9 & 66.2 & 62.5 & \\
\hline Overweight and obesity (\%) & 19.1 & 24.6 & 30.1 & 35.0 & \\
\hline \multicolumn{6}{|l|}{ Smoking status (\%) } \\
\hline Never smoker & 17.9 & 20.9 & 26.4 & 26.8 & $<0.001$ \\
\hline Past smoker & 18.6 & 23.4 & 27.6 & 43.1 & \\
\hline Current smoker & 63.5 & 55.8 & 46.0 & 30.1 & \\
\hline Salt intake ${ }^{c}$ (g per day) & $15.1(5.6)$ & $14.7(4.6)$ & $14.5(5.9)$ & $12.0(4.6)$ & $<0.001$ \\
\hline $\mathrm{SBP}(\mathrm{mm} \mathrm{Hg})$ (s.d.) & $138.0(20.9)$ & $137.4(19.9)$ & $137.9(19.7)$ & $137.7(18.4)$ & 0.552 \\
\hline DBP $(m m ~ H g)$ (s.d.) & $83.6(12.4)$ & $83.6(11.6)$ & $83.3(11.9)$ & $83.3(11.0)$ & 0.652 \\
\hline Antihypertensive drug use & 10.1 & 13.7 & 20.1 & 30.8 & $<0.001$ \\
\hline \multicolumn{6}{|l|}{ Women } \\
\hline Number of participants & 5803 & 4648 & 3139 & 1466 & \\
\hline Number of hypertension (\%) & $2346(40.4)$ & $1975(42.5)$ & $1353(43.1)$ & $657(44.8)$ & \\
\hline Mean age (years) (s.d.) & $50.0(12.9)$ & $51.7(13.1)$ & $54.3(13.1)$ & $57.7(13.7)$ & $<0.001$ \\
\hline Mean BMI $\left(\mathrm{kg} \mathrm{m}^{-2}\right)$ (s.d.) & $22.8(3.4)$ & 22.9 (3.3) & $23.0(3.5)$ & $22.8(3.5)$ & 0.082 \\
\hline Underweight (\%) & 7.2 & 6.5 & 7.0 & 7.6 & 0.200 \\
\hline Past drinker & 1.7 & 1.1 & 1.5 & 1.4 & \\
\hline Habitual drinker & 20.5 & 6.7 & 9.1 & 6.6 & \\
\hline Salt intake (g per day) & $13.0(4.7)$ & $12.8(4.0)$ & $12.6(5.1)$ & $10.4(4.1)$ & $<0.001$ \\
\hline $\mathrm{SBP}(\mathrm{mm} \mathrm{Hg})$ (s.d.) & $133.5(21.5)$ & $133.0(20.5)$ & $132.2(21.7)$ & $130.8(19.8)$ & $<0.001$ \\
\hline $\mathrm{DBP}(\mathrm{mm} \mathrm{Hg})$ (s.d.) & $79.6(12.0)$ & $79.5(11.7)$ & $78.9(12.3)$ & $78.3(10.8)$ & $<0.001$ \\
\hline Antihypertensive drug use & 11.6 & 15.9 & 18.8 & 23.0 & $<0.001$ \\
\hline
\end{tabular}

Abbreviations: BMI, body mass index; DBP, diastolic blood pressure; SBP, systolic blood pressure; s.d., standard deviation.

${ }^{a} P$-values were calculated by chi-squared test (categorical variables), or analysis of variance (continuous variables).

bHypertension was defined as a systolic blood pressure $\geqslant 140 \mathrm{~mm} \mathrm{Hg}$, diastolic blood pressure $\geqslant 90 \mathrm{~mm} \mathrm{Hg}$ or the use of antihypertensive drugs.

cSalt intake was estimated by the weighing record method for three consecutive days.

Disorders in $1980,{ }^{11-13}$ the fourth National Survey on Circulatory Disorders in $1990,{ }^{14-16}$ and the National Health and Nutrition Survey in $2010 .{ }^{17}$ We also used data from the fifth National Survey on Circulatory Disorders in $2000 .{ }^{18}$ Community-based participants in 300 census tracts were randomly selected from health districts throughout Japan for all surveys. Medical examinations, blood pressure measurements, blood tests and a self-administered questionnaire about lifestyle were conducted among 10546 participants aged $\geqslant 30$ years in 1980,8383 participants aged $\geqslant 30$ years in 1990,5565 participants aged $\geqslant 30$ years in 2000 and 2898 participants aged $\geqslant 20$ years in 2010.

For the current analysis, we excluded participants without data on body mass index (BMI; 1980: 2 participants, 1990: 122 participants, 2000: 5 participants and 2010: 10 participants) and participants who were aged $<30$ years or $\geqslant 80$ years (1980: 173 participants, 1990: 256 participants, 2000: 233 participants and
2010: 341 participants). Consequently, a final total of 10371 participants (men: 4568, women: 5803) in 1980, 8005 participants (men: 3357, women: 4648) in 1990, 5327 participants (men: 2188, women: 3139) in 2000 and 2547 participants (men: 1081, women: 1466) in 2010 were included in the study analysis.

The study protocol was approved by the Review Board of Shiga University of Medical Science.

\section{Body mass index}

BMI was calculated as measured weight divided by the square of measured height $\left(\mathrm{kg} \mathrm{m}^{-2}\right)$. We divided the participants into groups according to the following BMI categories: < 18.5 (underweight), 18.5-24.9 (normal weight) and $\geqslant 25.0 \mathrm{~kg} \mathrm{~m}^{-2}$ (overweight and obese). ${ }^{19}$ In Japan, the prevalence of a BMI $\geqslant 30 \mathrm{~kg} \mathrm{~m}^{-2}$ is only $3 \%{ }^{20}$ 


\section{Blood pressure}

Blood pressures were measured once in 1980 and 1990 and twice in 2000 and 2010 by trained observers using a standard mercury sphygmomanometer on the right arm of seated participants after being at rest for $>5 \mathrm{~min} .{ }^{18}$ We used the first blood pressure values in 2000 and 2010 to ensure comparability between periods. Information on the use of antihypertensive drugs was obtained by public health nurses. Hypertension was defined as a systolic blood pressure $\geqslant 140 \mathrm{~mm} \mathrm{Hg}$, diastolic blood pressure $\geqslant 90 \mathrm{~mm} \mathrm{Hg}$ or the use of antihypertensive drugs. ${ }^{21}$

\section{Statistical analysis}

The age-standardized prevalences of overweight and obesity and of hypertension in men and women were calculated by the direct method using the Japanese population aged $\geqslant 30$ years from the 2010 census. $^{22}$ Five-year age groups (30-34, 35-39, 40-44, 45-49, 50-54, 55-59, 60-64, $65-69,70-74$ and 75-79 years) were used for this standardization. We also calculated the age-standardized prevalence of hypertension among participants, stratified by normal weight, or overweight and obesity.

The odds ratios (ORs) and 95\% confidence intervals for hypertension were compared for overweight and obese participants with normal-weight participants. These statistics were calculated by multiple logistic regression analyses after adjusting for age (continuous), smoking status (never smoker, past smoker and current smoker), alcohol consumption (nonhabitual drinker, past drinker and habitual drinker) and salt intake (g per day) in each period. A habitual drinker was defined as one drink $\geqslant 3$ days per week and consuming $\geqslant 22.4 \mathrm{~g}$ per day of alcohol. Salt intake was estimated by the weighed food record method for three consecutive days. ${ }^{23}$ The trend of ORs during periods was assessed using linear regression weighted by the inverse of the variance of ORs in each year. ${ }^{24}$

The data were analyzed with SAS Release 9.4 software (SAS Institute, Cary, NC, USA). All $P$-values were two-tailed, and differences at $P<0.05$ were accepted as statistically significant.

\section{RESULTS}

Characteristics in 1980, 1990, 2000 and 2010

The characteristics of the study participants are shown for each year (Table 1). In both sexes, increasing trends of mean age and antihypertensive drug use were observed, as was a decreasing trend in salt intake over the three decades. An increasing trend of mean BMI and a decreasing trend of the proportion of current smokers and habitual drinkers was also observed in men. The proportion percentage of those who had never smoked and those who were habitual

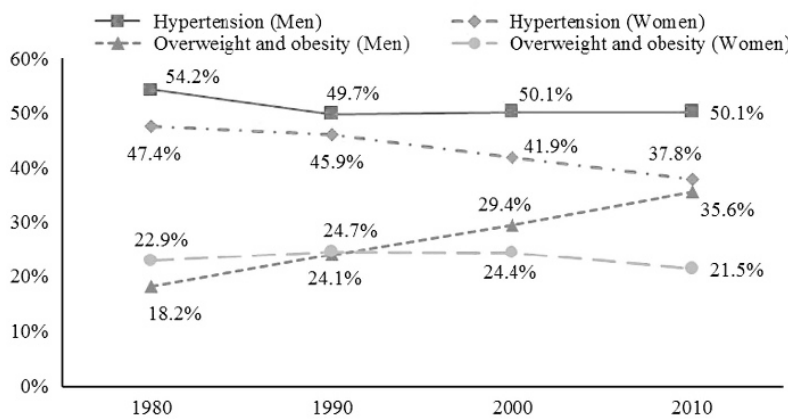

Figure 1 Age-standardized prevalence of hypertension and of overweight and obesity in participants who were recruited from national surveys in 1980 , 1990, 2000 and 2010, Japan. Age-standardized prevalence of hypertension, and overweight and obesity was calculated by the direct method using the Japanese population aged $\geqslant 30$ years from the 2010 census in each year. Hypertension was defined as a systolic blood pressure $\geqslant 140 \mathrm{~mm} \mathrm{Hg}$, diastolic blood pressure $\geqslant 90 \mathrm{~mm} \mathrm{Hg}$ or the use of antihypertensive drugs. Overweight and obesity were defined as BMI $\geqslant 25.0 \mathrm{~kg} \mathrm{~m}^{-2}$. A full color version of this figure is available at Hypertension Research online. drinkers was the highest in 1980. A decreasing trend in mean blood pressure level was observed in women.

\section{Age-standardized prevalence of obesity and hypertension}

The age-standardized prevalences of overweight and obesity and of hypertension are shown in each period among men and women (Figure 1). Even though the age-standardized prevalence of overweight and obesity have apparently increased in men and remained stable in women during this 30-year period, hypertension has apparently decreased in both sexes. The age-standardized prevalence of overweight and obesity increased by $17.4 \%$ points (1980: $18.2 \%$, 2010: $35.6 \%$ ) in men and decreased by $1.4 \%$ points (1980: $22.9 \%$, 2010: $21.5 \%$ ) in women. Hypertension also decreased by $4.1 \%$ points (1980: $54.2 \%, 2010: 50.1 \%$ ) in men and by $9.6 \%$ points (1980: $47.4 \%$, 2010: $37.8 \%$ ) in women.

However, compared with normal-weight participants, the reduction of age-standardized prevalence of hypertension from 1980 to 2010 was $8.0 \%$ points less in men and $7.8 \%$ points less in women among overweight and obese participants (Figure 2). In normal-weight participants, the corresponding rates decreased by $9.7 \%$ points in men (1980: $52.8 \%, 2010: 43.1 \%$ ) and by $11.0 \%$ points in women (1980: 44.9\%, 2010: 33.9\%) over 30 years. In overweight and obese participants, these rates decreased by $1.7 \%$ points in men (1980: $65.0 \%, 2010$ : $63.3 \%$ ) and by $3.2 \%$ points in women (1980: $59.8 \%, 2010: 56.6 \%$ ).

\section{Hypertension risk by obesity}

The ORs (95\% confidence intervals) for hypertension in overweight and obese participants compared with normal-weight participants are shown for each period from 1980 to 2010 (Figure 3). We observed an 1.5-fold significantly increased impact of overweight and obesity on hypertension during this time period ( $P=0.040$ in men and 0.006 in women). The multivariable-adjusted ORs in women were higher than those in men in each period. In 1980 and 2010, the multivariable-adjusted ORs (95\% confidence intervals) were $1.94(1.64,2.28)$ and $2.82(2.07,3.83)$ in men, and $2.37(2.05,2.73)$ and $3.48(2.57,4.72)$ in women.

\section{DISCUSSION}

The present results indicate that although the secular trend of prevalence of hypertension decreased in Japanese participants during a 30-year period, overweight and obesity increased in men and remained stable among women recruited nationally. The overweight and obesity risk on hypertension increased significantly, $\sim 1.5$-fold between 1980 and 2010. Currently, the impact of overweight and obesity on hypertension is stronger than that in previous decades.

Our previous report showed that the impact of overweight and obesity on hypertension had increased between 1980 and $1990 .{ }^{10}$ The present report showed that the impact of overweight and obesity on hypertension has continued to increase over the past 30 years.

However, even though the impact of overweight and obesity on hypertension has increased, the prevalence of hypertension has decreased in Japan. Similar trends of a decreasing prevalence of hypertension and increasing prevalence of obesity have been observed in other Western countries. ${ }^{25-28}$ This discrepancy might be caused by the decreasing prevalence of other determinants for hypertension. ${ }^{8,9}$ For example, in Japan, even though the difference in age during the survey years was not adjusted for, the amount of salt intake estimated by the weighed food record method for 3 consecutive days, which is the major determinant of hypertension, has decreased by $2.3 \mathrm{~g}$ per day during this period (1980: $12.5 \mathrm{~g}$ per day, 2010: $10.2 \mathrm{~g}$ per day). ${ }^{17,29}$ Systolic blood pressure has decreased $1-4 \mathrm{~mm} \mathrm{Hg}$ with a $3 \mathrm{~g}$ per day decrease in salt intake. ${ }^{30,31}$ Similarly, vegetable intake has increased as 


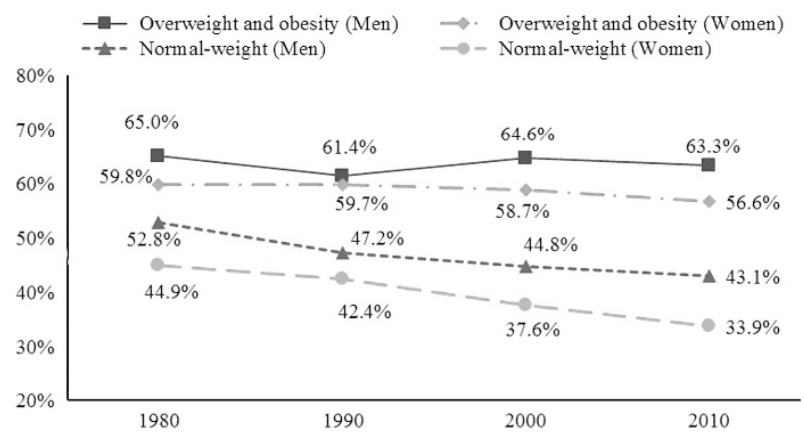

Figure 2 Age-standardized prevalence of hypertension stratified by normal weight, and overweight and obesity in participants who were recruited from national surveys in 1980, 1990, 2000 and 2010, Japan. Age-standardized prevalence of hypertension was calculated by the direct method using the Japanese population aged $\geqslant 30$ years from the 2010 census in each year. Hypertension was defined as a systolic blood pressure $\geqslant 140 \mathrm{~mm} \mathrm{Hg}$, diastolic blood pressure $\geqslant 90 \mathrm{~mm} \mathrm{Hg}$, or the use of antihypertensive drugs. Normal weight and obesity were defined as $\mathrm{BMI}=18.5-24.9$ and $\geqslant 25.0 \mathrm{~kg} \mathrm{~m}^{-2}$, respectively. A full color version of this figure is available at Hypertension Research online.

well (1980: 243.3 g per day, 2010: 267.9 g per day). ${ }^{17,29}$ Conversely, the prevalence of habitual alcohol consumption has decreased. ${ }^{17}$ The intake of vegetables and alcohol is an important determinant for hypertension. ${ }^{30}$ For these reasons, we considered whether the impact of overweight and obesity on hypertension has strengthened relatively rather than absolutely during the past 30 years. Thus, whereas the prevalence of hypertension has been decreasing, it may increase again in the future. In Japan, the prevalence of hypertension did not decrease during the last decade in men aged $\geqslant 50$ years, likely due to the increasing trend in overweight and obesity. ${ }^{2}$

A major strength of our study is that study participants were recruited from 300 community-based census tracts, which were randomly selected from all over Japan. Height, weight and blood pressure were measured by standardized methods in each national survey over a 30-year period. In addition, we adjusted for salt intake in a statistical model. Such a study is impossible to conduct in other Asian countries, because they do not have comparable long-term mature nutritional data in their national data. However, limitations of our study should also be considered. First, the present study was based on cross-sectional studies at each previous time period. Some overweight- and obesity-related hypertensive participants may be categorized as normal weight because they tried to lose weight. As a result, there is a possibility that the present results underestimate the impact of overweight and obesity on hypertension. However, we consider the impact of this misclassification on the present results as minimal because blood pressure levels also may have decreased following a body weight reduction among the participants with obesity-related hypertension. Second, the number of participants has decreased in national surveys. It is possible that comparability between each national survey has not been preserved because of selection bias. Third, we could not estimate the impact on hypertension divided by overweight and obesity because of a lower prevalence of obesity $\left(\mathrm{BMI} \geqslant 30 \mathrm{~kg} \mathrm{~m}^{-2}\right.$ ) in Japan (1980: 2.1\%, 1990: 2.5\%, 2000: 3.2\%, 2010: $3.4 \%) .{ }^{20}$ The present results mainly reflected the impact of overweight (BMI: $25.0-29.9 \mathrm{~kg} \mathrm{~m}^{-2}$ ). Although there is a need for further study, contributions to hypertension are likely stronger in more obese Westernized countries during the period under review. Fourth, compared with women in 1980, the present results overestimated the risk of hypertension among women in later periods

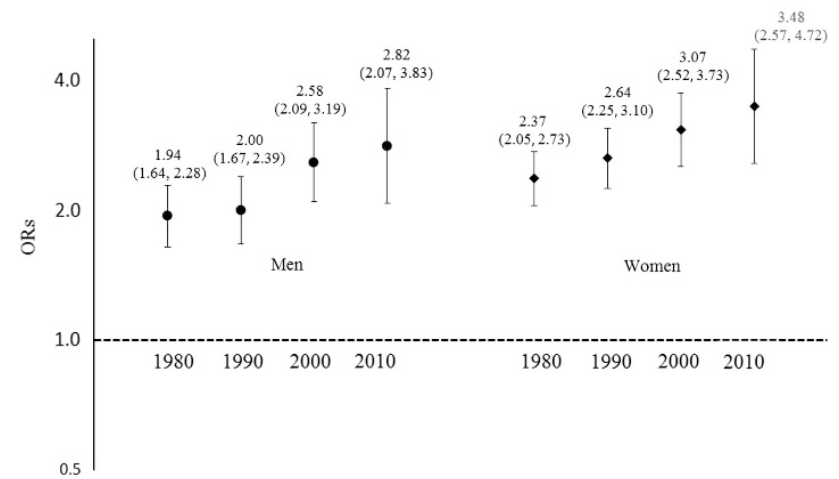

Figure 3 The ORs (95\% Cls) for hypertension in overweight and obese participants compared with normal-weight participants who were recruited from national surveys in 1980, 1990, 2000 and 2010, Japan. The ORs were adjusted for age, smoking status, alcohol consumption and salt intake. Hypertension was defined as a systolic blood pressure $\geqslant 140 \mathrm{~mm} \mathrm{Hg}$, diastolic blood pressure $\geqslant 90 \mathrm{~mm} \mathrm{Hg}$ or the use of antihypertensive drugs. $\mathrm{OR}$, odds ratio; $\mathrm{Cl}$, confidence interval.

because the prevalence of postmenopausal women has increased over the last 30 years. The mean age has also increased over this period (1980: 50.0 years, 2010: 58.6 years). It is well known that the prevalence of hypertension, overweight and obesity increases after menopause. However, we could not adjust for this effect because there is no information available on menopausal status.

In conclusion, overweight and obesity have been a major risk factor for hypertension during the past 30 years in Japan. In future, a decreasing tendency in the prevalence of hypertension might change to an increasing tendency because of an increased prevalence of overweight and obesity. This increasing trend of prevalence in overweight and obese participants has occurred not only in developed countries but also in developing countries. ${ }^{32}$ In addition to the relationship between excessive body mass, diabetes and other adverse health conditions, the rise in associations with hypertension adds increased importance for encouraging weight control. Preventing people from being overweight and obese will become more important for the prevention of hypertension in Japan and other Asian countries. We need to tackle the overweight and obesity epidemic and work toward its prevention.

\section{CONFLICT OF INTEREST}

The authors declare no conflict of interest.

\section{ACKNOWLEDGEMENTS}

We thank all the public health centers that cooperated with our study. The members of the NIPPON DATA80/90/2010 Research Group are listed below. This study was supported by a Grant-in-Aid from the Ministry of Health, Labor and Welfare under the auspices of the Japanese Association for Cerebrocardiovascular Disease Control, a Research Grant for Cardiovascular Diseases (7A-2) from the Ministry of Health, Labor and Welfare, and a Health and Labor Sciences Research Grant, Japan (Comprehensive Research on Aging and Health (H11-Chouju-046, H14-Chouju-003, H17-Chouju-012, H19-Chouju-Ippan-014) and Comprehensive Research on Life-Style Related Diseases including Cardiovascular Diseases and Diabetes Mellitus (H22-Jyunkankitou-Seisyu-Sitei-017, H25-Jyunkankitou-Seisyu-Sitei-022)).

Author contributions: $\mathrm{MN}, \mathrm{T}$ Ohkubo and $\mathrm{KM}$ contributed to the design of the study. T Ohkubo, YM, NT, AK, NM, YS, NN, NO, T Okamura, AO, HU and $\mathrm{KM}$ participated in the data collection. MN, T Ohkubo, YM, RD and KM participated in the data analysis. MN, T Ohkubo and KM participated in writing the report. All authors participated in critical revision of the manuscript and approved the final version of the report for submission. 


\section{THE NIPPON DATA80/90/2010 RESEARCH GROUP}

Chairpersons: NIPPON DTA80/90: Hirotsugu Ueshima (Department of Public Health, Shiga University of Medical Science, Otsu, Shiga). NIPPON DTA2010: Katsuyuki Miura (Department of Public Health, Shiga University of Medical Science, Otsu, Shiga).: Co-chairpersons: NIPPON DTA80/90: Akira Okayama (Research Institute of Strategy for Prevention, Tokyo) for the NIPPON DATA80, and Tomonori Okamura (Department of Preventive Medicine and Public Health, Keio University, Tokyo) for the NIPPON DATA90.: NIPPON DTA2010: Akira Okayama (Research Institute of Strategy for Prevention, Tokyo), and Tomonori Okamura (Department of Preventive Medicine and Public Health, Keio University, Tokyo).: Participating researchers: Hirotsugu Ueshima (Department of Public Health, Shiga University of Medical Science, Otsu, Shiga), Akira Okayama (Research Institute of Strategy for Prevention, Tokyo), Tomonori Okamura (Department of Preventive Medicine and Public Health, School of Medicine, Keio University, Tokyo), Shigeyuki Saitoh (Sapporo Medical University School of Health Science, Sapporo, Hokkaido), Kiyomi Sakata (Department of Hygiene and Preventive Medicine, Iwate Medical University, Morioka, Iwate), Atsushi Hozawa (Department of Preventive Medicine and Epidemiology, Tohoku Medical Megabank Organization, Tohoku University, Sendai, Miyagi), Takehito Hayakawa (Department of Hygiene and Preventive Medicine, Fukushima Medical University, School of Medicine, Fukushima), Yosikazu Nakamura (Department of Public Health, Jichi Medical University, Shimotsuke, Tochigi), Nobuo Nishi (Center for International Collaboration and Partnership National Institute of Health and Nutrition National Institutes of Biomedical Innovation, Health and Nutrition, Tokyo), Nagako Okuda (Department of Health and Nutrition, University of Human Arts and Sciences, Saitama), Tomonori Okamura (Department of Preventive Medicine and Public Health, Keio University, Tokyo), Yoshitaka Murakami (Department of Medical Statistics, Toho University School of Medicine, Tokyo), Takayoshi Ohkubo (Department of Hygiene and Public Health, Teikyo University School of Medicine, Tokyo), Fumiyoshi Kasagi (Institute of Radiation Epidemiology, Radiation Effects Association, Tokyo), Toru Izumi (Faculty of Medicine, Kitasato University, Sagamihara, Kanagawa), Yasuhiro Matsumura (Faculty of Health and Nutrition, Bunkyo University, Chigasaki, Kanagawa), Toshiyuki Ojima (Department of Community Health and Preventive Medicine, Hamamatsu University School of Medicine, Hamamatsu, Shizuoka), Koji Tamakoshi (Department of Public Health and Health Information Dynamics, Nagoya University Graduate School of Medicine, Nagoya, Aichi), Hideaki Nakagawa (Department of Epidemiology and Public Health, Kanazawa Medical University, Kanazawa, Ishikawa), Yoshikuni Kita (Faculty of Nursing Science, Department of Nursing Science, Tsuruga Nursing University, Tsuruga), Katsuyuki Miura, Aya Kadota (Department of Public Health, Shiga University of Medical Science, Otsu, Shiga), Naomi Miyamatsu (Department of Clinical Nursing Science Lecture, Shiga University of Medical Science, Otsu, Shiga), Yasuyuki Nakamura (Cardiovascular Epidemiology, Kyoto Women's University, Kyoto), Katsushi Yoshita (Osaka City University Graduate School of Human Life Science, Osaka), Yoshihiro Miyamoto (Department of Preventive Cardiology, National Cerebral and Cardiovascular Center, Suita, Osaka), Kazunori Kodama (Radiation Effects Research Foundation, Hiroshima) and Yutaka Kiyohara (Department of Environmental Medicine, Kyushu University, Fukuoka).

1 Ueshima H. Explanation for the Japanese paradox: prevention of increase in coronary heart disease and reduction in stroke. J Atheroscler Thromb 2007; 14: 278-286.

2 Miura K, Nagai M, Ohkubo T. Epidemiology of hypertension in Japan: where are we now? Circ J 2013; 77: 2226-2231.

3 Yatsuya H, Yamagishi K, Iso H. Adiposity and risk of cardiovascular diseases in Japan: secular trend, individual level associations and causal pathway - implications for the prevention of cardiovascular diseases in societies with rapid economic development. EPMA J 2011; 2: 65-73.

4 Ogihara T, Kikuchi K, Matsuoka H, Fujita T, Higaki J, Horiuchi M, Imai Y, Imaizumi T, Ito S, Iwao H, Kario K, Kawano Y, Kim-Mitsuyama S, Kimura G, Matsubara H, Matsuura H, Naruse M, Saito I, Shimada K, Shimamoto K, Suzuki H, Takishita S, Tanahashi N, Tsuchihashi T, Uchiyama M, Ueda S, Ueshima H, Umemura S, Ishimitsu T, Rakugi H. The Japanese Society of Hypertension Guidelines for the Management of Hypertension (JSH 2009). Hypertens Res 2009; 32: 3-107.

5 Ministry of Health, Labour and Welfare (2011). National Health and Nutrition Survey in Japan. http://www.mhlw.go.jp/bunya/kenkou/eiyou/dl/h23-houkoku.pdf, in Japanese.
6 Yoshiike N, Seino F, Tajima S, Arai Y, Kawano M, Furuhata T, Inoue S. Twenty-yea changes in the prevalence of overweight in Japanese adults: the National Nutrition Survey 1976-95. Obes Rev 2002; 3: 183-190.

7 Funatogawa I, Funatogawa T, Nakao M, Karita K, Yano E. Changes in body mass index by birth cohort in Japanese adults: results from the National Nutrition Survey of Japan 1956-2005. Int J Epidemiol 2009; 38: 83-92.

8 Ikeda N, Gakidou E, Hasegawa T, Murray CJ. Understanding the decline of mean systolic blood pressure in Japan: an analysis of pooled data from the National Nutrition Survey, 1986-2002. Bull World Health Organ 2008; 86: 978-988.

9 Ueshima H, Tatara K, Asakura S, Okamoto M. Declining trends in blood pressure level and the prevalence of hypertension, and changes in related factors in Japan, 1956-1980. J Chronic Dis 1987; 40: 137-147.

10 Nakamura K, Okamura T, Hayakawa T, Hozawa A, Kadowaki T, Murakami Y, Kita Y, Okayama A, Ueshima $\mathrm{H}$. The proportion of individuals with obesity-induced hypertension among total hypertensives in a general Japanese population: NIPPON DATA80, 90. Eur J Epidemiol 2007; 22: 691-698.

11 Ueshima H. Nippon Data. Nihon Rinsho 2006; 64: 108-111, in Japanease.

12 Okamura T, Kadowaki T, Hayakawa T, Kita Y, Okayama A, Ueshima H. What cause of mortality can we predict by cholesterol screening in the Japanese general population? J Intern Med 2003; 253: 169-180.

13 NIPPON DATA80 Research Group. Risk assessment chart for death from cardiovascula disease based on a 19-year follow-up study of a Japanese representative population. Circ J 2006; 70: 1249-1255.

14 Okamura T, Hayakawa T, Kadowaki T, Kita Y, Okayama A, Elliott P, Ueshima H. Resting heart rate and cause-specific death in a 16.5-year cohort study of the Japanese general population. Am Heart J 2004; 147: 1024-1032.

15 Kadota A, Hozawa A, Okamura T, Kadowak T, Nakmaura K, Murakami Y, Hayhakawa T, Kita Y, Okayama A, Nakamura Y, Kashiwagi A, Ueshima H. Relationship between metabolic risk factor clustering and cardiovascular mortality stratified by high blood glucose and obesity: NIPPON DATA90, 1990-2000. Diabetes Care 2007; 30 : 1533-1538.

16 Nakamura K, Okamura T, Hayakawa T, Kadowaki T, Kita Y, Ohnishi H, Saitoh S, Sakata K, Okayama A, Ueshima H. Chronic kidney disease is a risk factor for cardiovascular death in a community-based population in Japan: NIPPON DATA90. Circ J 2006; 70: 954-959.

17 Ministry of Health, Labour and Welfare 2010. National Health and Nutrition Survey in Japan. http://www.mhlw.go.jp/bunya/kenkou/eiyou/dl/h22-houkoku-01.pdf, in Japanese.

18 Japan Heart Foundation. The Fifth National Survey on Circulatory Disorders. Chuohoki Publishers: Tokyo, 2003, in Japanese.

19 Examination Committee of Criteria for 'Obesity Disease' in Japan. New criteria for 'obesity disease' in Japan. Circ J 2002; 66: 987-992.

20 Yoshiike N, Matsumura Y, Zaman MM, Yamaguchi M. Descriptive epidemiology of body mass index in Japanese adults in a representative sample from the National Nutrition Survey 1990-1994. Int J Obes Relat Metab Disord 1998; 22: 684-687.

21 Chobanian AV, Bakris GL, Black HR, Cushman WC, Green LA, Izzo JL Jr, Jones DW, Materson BJ, Oparil S, Wright JT Jr, Roccella EJ. Seventh report of the Joint National Committee on Prevention, Detection, Evaluation, and Treatment of High Blood Pressure. Hypertension 2003; 42: 1206-1252.

22 Statistic Bureau, Ministry of Internal Affairs and Communications. 2011 Population Census of Japan. http://www.e-stat.go.jp/SG1/estat/NewList.do?tid $=000001039448$, in Japanese.

23 Okuda N, Miura K, Yoshita K, Matsumura Y, Okayama A, Nakamura Y, Okamura T, Saitoh S, Sakata K, Ojima T, Turin TC, Ueshima H. Integration of data from NIPPON DATA80/90 and National Nutrition Survey in Japan: for cohort studies of representative Japanese on nutrition. J Epidemiol 2010; 20: S506-S514

24 Staessen JA, Wang JG, Thijs L. Cardiovascular protection and blood pressure reduction: a meta-analysis. Lancet 2001; 358: 1305-1315.

25 Gregg EW, Cheng YJ, Cadwell BL, Imperatore G, Williams DE, Flegal KM, Narayan KM, Williamson DF. Secular trends in cardiovascular disease risk factors according to body mass index in US adults. JAMA 2005; 293: 1868-1874.

26 Kastarinen MJ, Nissinen AM, Vartiainen EA, Jousilahti PJ, Korhonen HJ, Puska PM, Tuomilehto. Blood pressure levels and obesity trends in hypertensive and normotensive Finnish population from 1982 to 1997. J Hypertens 2000; 18: 255-262.

27 Rosengren A, Eriksson H, Hansson PO, Svardsudd K, Wilhelmsen L, Johansson S, Welin $\mathrm{C}$, Welin L. Obesity and trends in cardiovascular risk factors over 40 years in Swedish men aged 50. J Intern Med 2009; 266: 268-276.

28 Borodulin K, Vartiainen E, Peltonen M, Jousilahti P, Juolevi A, Laatikainen T, Männistö S, Salomaa V, Sundvall J, Puska P. Forty-year trends in cardiovascular risk factors in Finland. Eur J Public Health 2014; 25: 539-546.

29 Ministry of health and Welfare. The National Nutrition Survey in Japan, 1980. Daiichi Shuppan: Tokyo, 1982, in Japanese.

30 Chobanian AV, Bakris GL, Black HR, Cushman WC, Green LA, Izzo JL Jr, Jones DQ, Materson BJ, Oparil S, Wright JT Jr, Roccella EJ. The Seventh Report of the Joint National Committee on Prevention, Detection, Evaluation, and Treatment of High Blood Pressure: the JNC 7 report. JAMA 2003; 289: 2560-2572.

31 Elliott P, Stamler J, Nichols R, Dyer AR, Stamler R, Kesteloot H, Marmot M. Intersalt revisited: further analyses of 24 hour sodium excretion and blood pressure within and across populations. Intersalt Cooperative Research Group. BMJ 1996; 312: 1249-1253.

$32 \mathrm{Ng} \mathrm{M}$, Fleming T, Robinson M, Thomson B, Graetz N, Margono C, Mullany EC, Biryukov S, Abbafati C, Abera SF, Abraham JP, Abu-Rmeileh NM, Achoki T, AlBuhairan FS, Alemu ZA, Alfonso R, Ali MK, Ali R, Guzman NA, Ammar W, Anwari P, Banerjee A, Barquera S, Basu S, Bennett DA, Bhutta Z, Blore J, Cabral N 
Nonato IC, Chang JC, Chowdhury R, Courville KJ, Criqui MH, Cundiff DK, Dabhadkar KC, Dandona L, Davis A, Dayama A, Dharmaratne SD, Ding EL, Durrani AM, Esteghamati A, Farzadfar F, Fay DF, Feigin VL, Flaxman A, Forouzanfar MH, Goto A, Green MA, Gupta R, Hafezi-Nejad N, Hankey GJ, Harewood HC, Havmoeller R, Hay S, Hernandez L, Husseini A, Idrisov BT, Ikeda N, Islami $F$, Jahangir $E$, Jassal SK, Jee $S H$, Jeffreys $M$, Jonas JB, Kabagambe EK, Khalifa SE, Kengne AP, Khader YS, Khang YH, Kim D, Kimokoti RW, Kinge JM, Kokubo Y, Kosen S, Kwan G, Lai T, Leinsalu M, Li Y, Liang X, Liu S, Logroscino G, Lotufo PA, Lu Y, Ma J, Mainoo NK, Mensah GA, Merriman TR, Mokdad AH,
Moschandreas J, Naghavi M, Naheed A, Nand D, Narayan KM, Nelson EL, Neuhouser ML, Nisar MI, Ohkubo T, Oti So, Pedroza A, Prabhakaran D, Roy N, Sampson U, Seo H, Sepanlou SG, Shibuya K, Shiri R, Shiue I, Singh GM, Singh JA, Skirbekk V, Stapelberg NJ, Sturua L, Sykes BL, Tobias M, Tran BX, Trasande L, Toyoshima H, van de Vijver S, Vasankari TJ, Veerman JL, Velasquez-Melendez G, Vlassov VV, Vollset SE, Vos T, Wang C, Wang X, Weiderpass E, Werdecker A, Wright JL, Yang YC, Yatsuya H, Yoon J, Yoon SJ, Zhao Y, Zhou M, Zhu S, Lopez AD, Murray CJ, Gakidou E. Global, regional and national prevalence of overweight and obesity in children and adults 1980-2013: a systematic analysis. Lancet 2014; 384: 766-781. 